\title{
Introduction of Subcutaneous Depot Medroxyprogesterone Acetate (DMPA-SC) Injectable Contraception at Facility and Community Levels: Pilot Results From 4 Districts of Uganda
}

\author{
George Odwe, ${ }^{a}$ Kate Gray, ${ }^{b}$ Annet Kyarimpa, ${ }^{c}$ Francis Obare, ${ }^{a}$ Grace Nagendi ${ }^{d}$
}

Over 1 year, the NGO-led project provided more than 14,000 units of DMPA-SC, mostly in community settings and to a substantial proportion (43\%) of young women. The share of injectables increased significantly, as did the volume of all methods provided, including short-acting, long-acting, and permanent methods.

\section{ABSTRACT}

Reproductive Health Uganda (RHU), a local NGO, introduced subcutaneous depot medroxyprogesterone acetate (DMPA-SC, brand name Sayana Press) in 4 districts of Uganda between April 2016 and March 2017. RHU trained public and private facility providers on all family planning methods including DMPA-SC; trained community health workers (known as village health teams, VHTs) to give family planning counseling, provide short-acting methods including DMPA-SC, and make referrals for long-acting and permanent methods; conducted mobile outreach and raised awareness of family planning; and provided family planning commodities. We used a retrospective cross-sectional evaluation design drawing on data from (1) in-depth interviews with 32 facility- and community-based providers; (2) key informant interviews with 7 policy makers and program staff; and (3) family planning program statistics from 4 RHU clinics, 26 mobile outreach sites, and 40 VHTs in 4 study districts. Data collection took place between April and June 2017 . Over 12 months, 14,273 units of DMPA-SC were provided in RHU clinics, by mobile outreach teams, and by VHTs. DMPA-SC units were mostly administered in community settings either by VHTs (70\%) or at mobile outreach events (26\%). A substantial proportion (43\%) of DMPA-SC units were administered to young people ( $<25$ years), a significantly higher proportion compared with other methods provided to this age group through the project $(P<.001)$, except condoms. In addition, a greater proportion of DMPA-SC units provided at the community level by VHTs were used by young people (45\%) compared with units provided at outreach (36\%) or in clinics (35\%). Overall, injectables (DMPA-SC and intramuscular DMPA combined) came to represent $43 \%$ of all contraceptive methods provided, up from a baseline of $20 \%$. This shift occurred despite significant increases in the volume of all other methods provided $(P<.001)$. Qualitative data revealed various factors that facilitated introduction, including comprehensive training, commodity availability, strong referral links, and early community engagement. RHU's experience supports the viability of community-based delivery of DMPA-SC and identifies opportunities to strengthen this approach. There is further evidence that DMPA-SC may be popular with young people, especially in community settings.

\section{INTRODUCTION}

$\mathrm{n}$ estimated 214 million women and girls in lowand middle-income countries (LMICs) would like to stop having children or delay their next birth for at least 2 years but are not using a modern contraceptive method and are therefore at risk of unintended pregnancy. ${ }^{1}$ Limited access to family planning services and restricted method choice have been cited as main reasons for high levels of unmet need for contraception in LMICs. ${ }^{2}$ In an effort to increase the availability of

\footnotetext{
a Population Council, Nairobi, Kenya.

b International Planned Parenthood Federation, London, United Kingdom.

${ }^{c}$ Reproductive Health Uganda, Kampala, Uganda.

d International Planned Parenthood Federation, Africa Region, Nairobi, Kenya. Correspondence to George Odwe lgodwe@popcouncil.org, godweus@gmail. com).
}

a range of contraceptive methods, and in doing so, potentially attract new voluntary family planning users, a new injectable contraceptive known as subcutaneous depot medroxyprogesterone acetate (DMPA-SC) has been developed. ${ }^{3}$

DMPA-SC is a 3-month, progestin-only injectable contraceptive containing $104 \mathrm{mg}$ of DMPA per $0.65 \mathrm{ml}$ dose that is administered into certain fatty areas under the skin. Sayana Press (a brand of DMPA-SC developed by Pfizer) combines the drug and needle in a single prefilled Uniject system (a trademark of Becton, Dickinson and Company), designed only for single use. The singleunit design makes DMPA-SC easy to transport and simple to administer as providers do not have to draw a measured dose into the syringe from a vial. ${ }^{4,5}$ These features make it suitable for community-based distribution and for women to administer themselves, thus avoiding 


\section{The single-unit design of Sayana Press makes it easy to transport and simple to administer.}

RHU provided
support in
training, demand
creation,
commodity supply,
and service
delivery in order
to integrate
DMPA-SC into
family planning
services at the
community and
facility levels.

the need for them to travel to a health facility. ${ }^{6}$ In 2018, the World Health Organization (WHO) included DMPA-SC in its revised Essential Medicines List. $^{7}$ DMPA-SC is currently approved for use in a number of sub-Saharan African countries including Burkina Faso, Niger, Senegal, and Uganda. ${ }^{8}$

To date, the bulk of evidence on DMPA-SC has come from high-quality research trials on the method's acceptability, efficacy, and safety. However, there is still much to learn about different models and approaches for DMPA-SC rollout and scale up. In 2016/2017, Reproductive Health Uganda (RHU)—a member association of the International Planned Parenthood Federation-implemented a 1-year project to increase learning on provision of DMPA-SC at the facility and community levels. The project, also known as the Sayana Press Learning Project, was implemented in 4 districts of Uganda-Kabale, Kabarole, Mbale, and Mbarara.

Estimates from the 2016 Uganda Demographic Health Survey show that about $41 \%$ of pregnancies in Uganda are unintended. ${ }^{9}$ Teenage pregnancy is also highly prevalent-approximately $25 \%$ of adolescent girls aged 15-19 in Uganda have begun childbearing. ${ }^{9}$ However, the modern contraceptive prevalence rate (mCPR) is modest at $35 \%$ among married women aged $15-49$ years. ${ }^{9}$ The Ugandan government has made commitments to the Family Planning 2020 (FP2020) initiative to improve access to family planning services, with the goal of reducing unmet need for family planning from $38 \%$ to $10 \%$ and increasing mCPR to $50 \%$ by $2020 .{ }^{10}$ To help achieve these targets, Uganda is implementing a communitybased health strategy allowing community health workers, known as village health teams (VHTs) in the country, to provide both family planning information and selected services including injectable contraceptives and other short-acting methods (condoms and oral pills) in their community. ${ }^{11-15}$ In 2014, the Ugandan government launched a pilot introduction of DMPA-SC through the VHT program across 28 districts to accelerate achievement of FP2020 goals. RHU was one of a range of partners involved in this initial pilot introduction of DMPA-SC and served as the first private-sector NGO clinic entry point for the DMPA-SC pilot in Gulu district, northern Uganda.

In this article, we document RHU's experience in introducing DMPA-SC services in 4 other districts of Uganda through various models, consisting of static clinics, community-based distribution through VHTs, and mobile outreach in remote communities by a team of trained providers. We also share lessons learned from RHU's experience in supporting the rollout of DMPA-SC from the perspective of key informants involved in the project including service providers, project staff, and government officials. The findings can inform policy makers and program implementers in other countries on how to introduce DMPA-SC into the range of available methods.

\section{PROJECT DESCRIPTION}

\section{Study Setting}

RHU is a Ugandan NGO with a network of 17 clinics across the country that offer integrated sexual and reproductive health information and services including comprehensive family planning, testing and treatment for HIV and other sexually transmitted infections, and cervical cancer screening. RHU provides these integrated services through clinic-based providers, mobile outreach teams, and community resource persons, including VHTs. RHU implemented the Sayana Press Learning Project from April 2016 through March 2017 in collaboration with the Ministry of Health $(\mathrm{MOH})$, mainly in partnership with public-sector facilities (health centers) in remote settings. In selecting project districts, RHU prioritized (1) districts with well-established RHU clinics offering a full range of voluntary family planning services and capacity to support local public-sector facilities and community health workers during the pilot, and (2) districts where no other DMPA-SC implementation had taken place through other pilots. Table 1 presents current reproductive health indicators for the sub regions where study districts are located.

Table 2 lists programmatic inputs. In order to achieve integration of DMPA-SC into the family planning service delivery structure at the community level and strengthen family planning services in static clinics, RHU provided support in 5 key areas: training; demand creation; commodity supply; partnerships and collaboration; and service delivery at community and facility levels.

\section{Training}

A total of 42 facility-based providers, mainly nurses, midwives, and clinical officers, primarily from public-sector facilities with outreach sites as well as from RHU's own facilities, were trained on DMPA-SC using modules developed by PATH. Public-sector providers also received refresher training on all family planning methods to be able to support mobile outreach services in their respective facility sites. In addition, RHU recruited 40 active VHTs (10 in each study district) and 
TABLE 1. Reproductive Health Indicators for Study Districts, Uganda, 2016

\begin{tabular}{llcccc}
\hline District & Subregion & TFR & $\begin{array}{c}\text { Teenage } \\
\text { Pregnancy (\%) }\end{array}$ & mCPR (\%) & $\begin{array}{c}\text { Unmet Need for Family } \\
\text { Planning (\%) }\end{array}$ \\
\hline Mbale & Bugisu & 5.6 & 28.2 & 43.2 & 22.1 \\
\hline Kabarole & Toro & 5.4 & 30.3 & 37.4 & 41.3 \\
\hline Mbarara & Ankole & 4.9 & 18.9 & 36.2 & 44.5 \\
\hline Kabale & Kigezo & 4.6 & 15.5 & 43.2 & NA \\
\hline National & & $\mathbf{5 . 4}$ & $\mathbf{2 4 . 8}$ & $\mathbf{3 4 . 8}$ & $\mathbf{3 1 . 9}$ \\
\hline
\end{tabular}

Abbreviations: NA, not available (due to small numbers of data); $m C P R$, modern contraceptive prevalence rate; TFR, total fertility rate. Source: UBOS and ICF $(2018)$. $^{9}$

trained them for 7 days using the MOH's national curriculum for VHTs and DMPA-SC training modules developed by PATH. The VHTs' training was aimed at improving their knowledge, skills, and competencies on counseling family planning clients on all methods; provision of short-acting methods including DMPA-SC; community mobilization; reporting; and referrals. To ensure service quality, RHU clinical staff conducted monthly supportive supervision meetings with VHTs participating in the project. At these meetings, existing $\mathrm{MOH}$ tools were used to assess and strengthen VHT skills.

\section{Demand Creation}

RHU supported VHTs to mobilize communities to attend outreach events and to provide information about family planning when visiting households in their communities. In addition, RHU providers conducted family planning health education sessions at health centers during outreach visits. The project also used the media (mainly radio talk shows), billboards, and community dialogue sessions to increase access to information about family planning, including DMPA-SC.

To update community stakeholders about the family planning services available through the project and to ensure community acceptance of planned activities, the project team held meetings with community leaders from project districts prior to implementation. Information about DMPA-SC was shared with participants during these stakeholder workshops.

\section{Commodity Supply}

In line with standard supply-chain processes in Uganda, public health facilities in project districts received commodities from the Ugandan National Medical Stores. Like all NGO partners that collaborated with the MOH to deliver family planning services in Uganda, RHU received contraceptive commodities including DMPA-SC via the Uganda Health Marketing Group (UHMG) and distributed them to all its service delivery points in the participating districts.

\section{Partnerships and Collaboration}

RHU was a member of the DMPA-SC coordination group that spearheaded the rollout of DMPA-SC services nationally. Members of the DMPA-SC coordination group met on a monthly basis to track DMPA-SC introduction progress, identify and respond to emerging challenges, and make decisions about national DMPA-SC introduction. The coordination group included representatives from the $\mathrm{MOH}$ and other NGOs implementing DMPA$\mathrm{SC}$ rollout activities in other districts. Members of the coordination group complemented each other to support DPMA-SC activities. For example, RHU adopted the DPMA-SC educational and training materials developed by PATH to train providers.

\section{Service Delivery}

RHU implemented the Sayana Press Learning Project within the existing family planning service delivery structures, via 3 principal channels: VHTs, static clinics, and mobile outreach. At the community level, the project supported integration of DMPA-SC into family planning service delivery via:

- 40 VHTs (10 from each district), who provided comprehensive family planning counseling; delivered DMPA-SC along with other short-acting methods to women in their homes and in community settings; and referred clients interested in long-acting methods to mobile health units, RHU clinics, or publicsector static clinics. To enable them to travel

\author{
DMPA-SC was \\ provided through \\ 3 principal \\ channels: village \\ health teams, \\ static clinics, and \\ mobile outreach.
}


TABLE 2. Sayana Press Learning Project Activities by Service Delivery Channel, Uganda, April 2016-March 2017

\section{Service Delivery Channels}

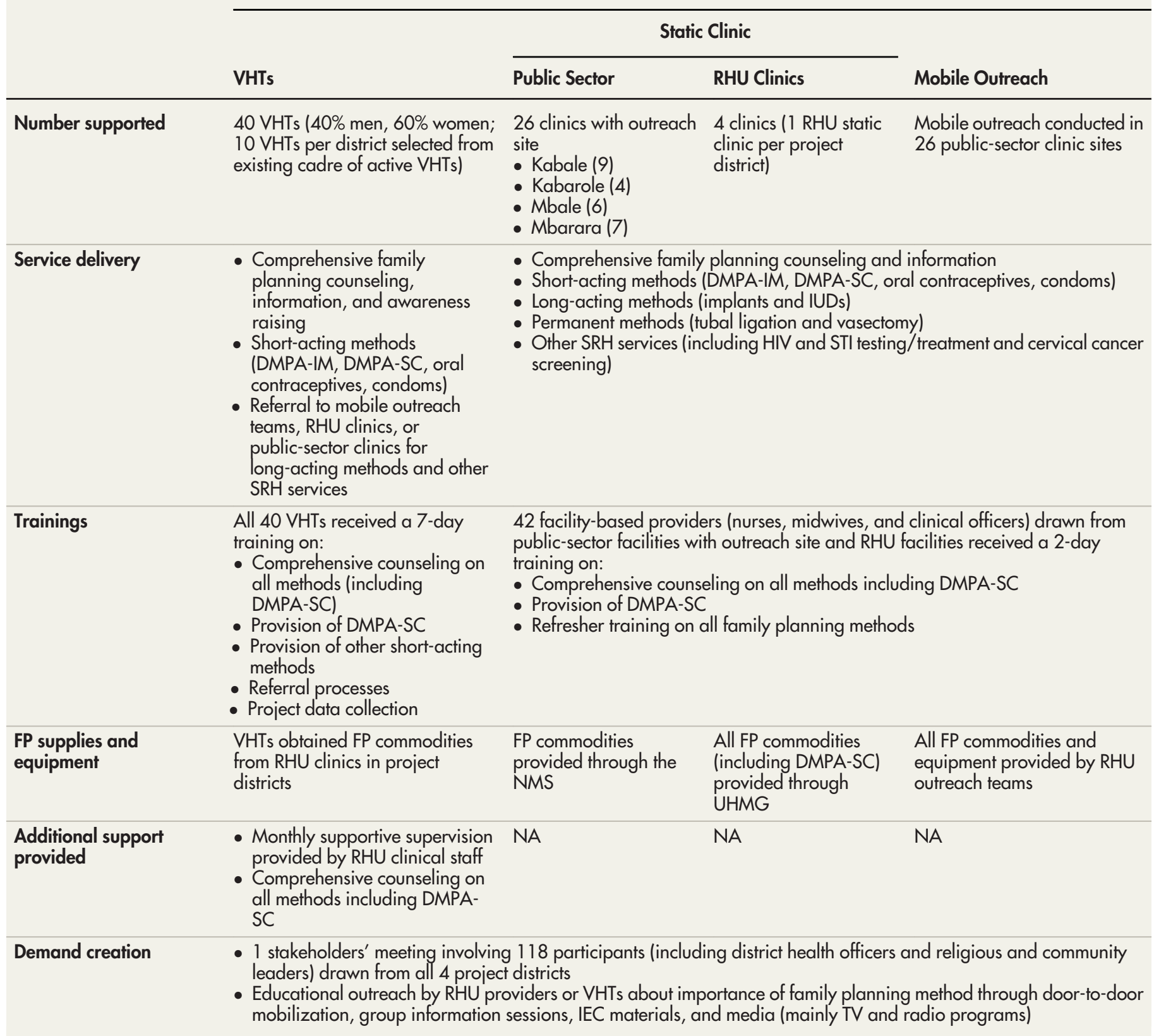

Abbreviations: DMPA-IM, intramuscular depot medroxyprogesterone acetate; DMPA-SC, subcutaneous depot medroxyprogesterone acetate; FP, family planning; IEC, information, education, and communication; IUD, intrauterine device; NA, not applicable; NMS, National Medical Stores; RHU,

Reproductive Health Uganda; SRH, sexual and reproductive health; STI, sexually transmitted infection; UHMG, Uganda Health Marketing Group; VHT,

village health team.

within their communities and to clinics to restock family planning commodities, VHTs received a monthly transportation allowance of approximately 30,000 Ugandan shillings (about US\$8 at 2018 exchange rates). In setting this allowance, the project used standard RHU rates for 2015/2016, which were lower than the rate paid by comparable NGOs but higher than the government rate of US\$3 per month. 
- Mobile outreach teams, who provided a mix of long- and short-acting family planning methods (including DMPA-SC). Each team consisted of 1 driver, at least 1 VHT to mobilize communities, and a mix of RHU outreach clinical staff and project-trained public-sector service providers-mainly nurses and midwives.

At the facility level, providers at RHU and government static clinics provided all family planning services including long-acting methods and DMPA-SC as a new method.

\section{METHODS}

We used a retrospective cross-sectional evaluation design, drawing on both qualitative and quantitative data. Data collection took place from April to June 2017 in the 4 project districts.

Qualitative data were collected through indepth interviews with 20 VHTs (5 per project district) and 12 facility-based health workers ( 4 from RHU clinics and 8 from public-sector facilities) to assess their experiences and their perceptions of enablers of and barriers to DMPA-SC service provision. Only providers who participated in the program were eligible for inclusion. In addition, we conducted 7 key informant interviews (2 national and 4 district-level policy makers and 1 program staff) to assess how the project was implemented and to seek their views on the feasibility of scaling up DMPA-SC services. Key informants were selected based on their role in the intervention. Written informed consent was obtained from all participants before conducting the interviews. Interviews were audio-recorded, transcribed, and translated into English when necessary.

Quantitative data were based on family planning service statistics extracted from RHU's static clinics, VHTs, and mobile outreach activities in the study districts. For each service delivery channel (i.e., static clinics, VHTs, and outreaches), information was collected on the number of family planning services provided by age category of recipients (below 25 years and 25 years or older). Family planning service data were captured using standard registers, which had been adapted to include DMPA-SC as a new family planning method. At the community level, VHTs captured family planning client records using VHT registers, which were submitted to RHU facilities on a monthly basis. Prior to the start of the project, RHU trained VHTs and RHU's facility-based providers on data collection, storage, and reporting procedures. Data from each service delivery unit were entered into RHU's District Health Information Software

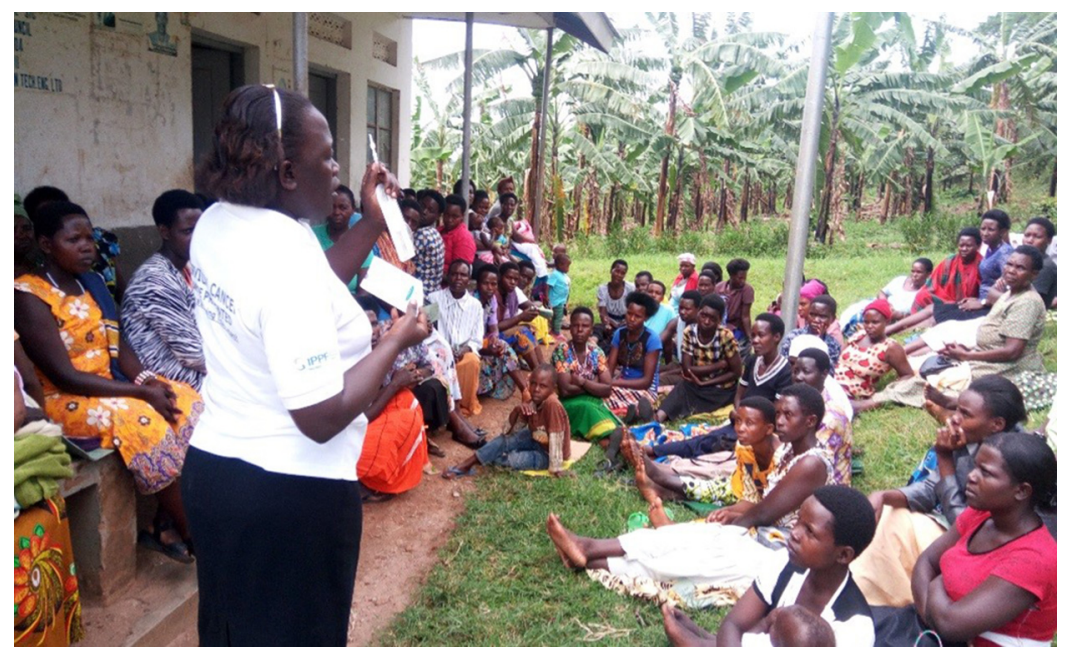

During an RHU outreach event in Kabarole district, Uganda, a provider shows women waiting for family planning services what Sayana Press looks like and provides information about the method. () 2016 Irene Kugonza/RHU.

(DHIS), which is a centralized platform. Information Management Assistants based at RHU clinics in each project district were responsible for data management and quality assurance across all service delivery points. In addition, monthly data quality assessment visits to RHU facilities were conducted by headquarters staff. We did not capture family planning data from the public health facilities in project sites as DMPA-SC had not been integrated into the $\mathrm{MOH}$ management information system by the time of this evaluation.

We downloaded family planning data into Microsoft Excel, and then exported the data to Stata version 11 for analysis. Quantitative data analysis involved generating descriptive statistics, mainly via cross-tabulations and frequencies, and conducting test on proportions of family planning services to examine whether there were any significant changes between the 6-month period prior to project implementation and the second 6-month period of project implementation (i.e., months 7 through 12 of project implementation). We used Impact 2 (version 5) to calculate coupleyear of protection (CYP) estimates. ${ }^{16}$ We analyzed qualitative data using content analysis by coding the data and identifying common themes based on the interview guides.

\section{Ethical Clearance}

Ethical approval for the study was obtained from the Population Council's Institutional Review Board (Protocol 762) and The AIDS Support Organization 
(TASO) Research Ethics Committee in Uganda (TASOREC/38/16-UG-REC-009). The Uganda National Council for Science and Technology (UNCST) granted administrative permission for the research (SS4225).

\section{RESULTS}

\section{Volume of DMPA-SC Units Provided}

More than

14,000 units of DMPA-SC were distributed over the 12-month project period.
A total of 14,273 units of DMPA-SC were distributed by VHTs, at RHU clinics, and through mobile outreach in project districts between April 2016 and March 2017 (Table 3). The mean number of units administered across all project sites and through all service delivery points (excluding public-sector static clinics) was 1,189 units per month, with a high of 1,757 units distributed in
March 2017 and a low of 200 units during the first month of implementation (April 2016).

There were some fluctuations in the monthly distribution of DMPA-SC during the project period (Figure 1). These fluctuations could be attributed mainly to program challenges such as delays by VHTs in replenishing their family planning stocks and delays in disbursal of funds to RHU and implementation teams.

\section{Volume of Family Planning Methods Provided}

Table 4 presents the number of all family planning methods delivered during the 12-month project period and for 6 months before the project began. A total of 82,254 family planning methods, representing approximately 24,500 CYPs, were

TABLE 3. Number of DMPA-SC Units Provided by Project District and Service Delivery Channel, Uganda, April 2016-March 2017

\begin{tabular}{lccccc}
\hline & \multicolumn{3}{c}{ Service Delivery Channel } \\
\cline { 2 - 5 } District & $\begin{array}{c}\text { Clinics } \\
\text { No. (\%) }\end{array}$ & $\begin{array}{c}\text { Outreach } \\
\text { No. }(\%)\end{array}$ & $\begin{array}{c}\text { VHTs } \\
\text { No. }(\%)\end{array}$ & $\begin{array}{c}\text { Total } \\
\text { No. }\end{array}$ & \multicolumn{2}{c}{$\begin{array}{c}\text { Monthly Average } \\
\text { No. }\end{array}$} \\
\hline Mbale & $131(2.7)$ & $1060(22.2)$ & $3589(75.1)$ & 4780 & 398 \\
\hline Kabarole & $110(3.5)$ & $881(28.0)$ & $2157(68.5)$ & 3148 & 262 \\
\hline Mbarara & $87(4.2)$ & $405(19.6)$ & $1579(76.2)$ & 2071 & 173 \\
\hline Kabale & $267(6.2)$ & $1388(32.5)$ & $2619(61.3)$ & 4274 & 356 \\
\hline Total & $595(4.2)$ & $\mathbf{3 7 3 4 ( 2 6 . 2 )}$ & $\mathbf{9 9 4 4 ( 6 9 . 7 )}$ & $\mathbf{1 4 , 2 7 3}$ & 1189 \\
\hline
\end{tabular}

Abbreviations: DMPA-SC, subcutaneous depot medroxyprogesterone acetate; VHT, village health team.

FIGURE 1. Monthly Trends in the Number of DMPA-SC Units Provided by District, Uganda, April 2016-March 2017

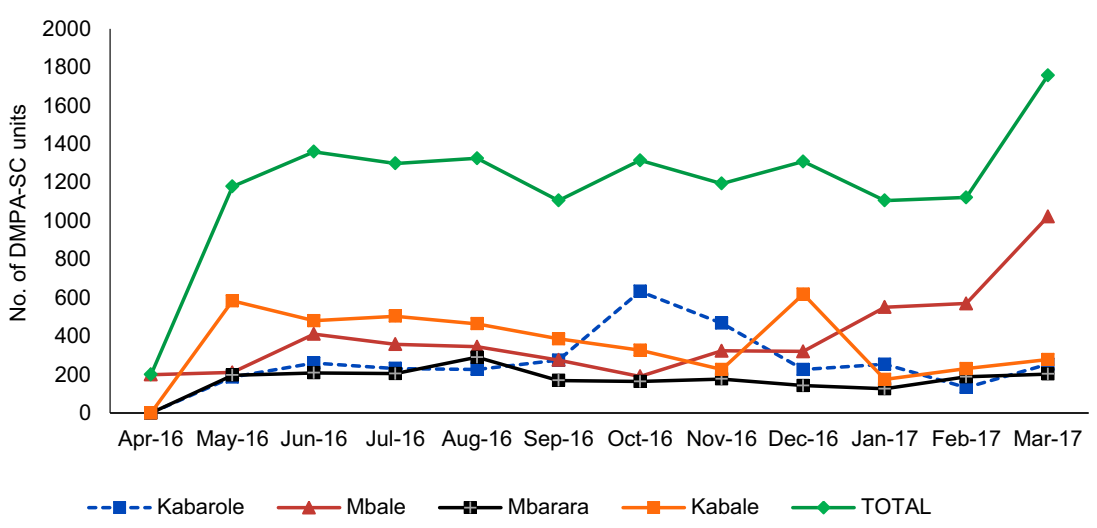

Abbreviation: DMPA-SC, subcutaneous depot medroxyprogesterone acetate. 
TABLE 4. Volume of Family Planning Methods Provided Before and During the Intervention by Contraceptive Method, 4 Districts of Uganda

\begin{tabular}{lcccr}
\hline Method & $\begin{array}{c}\text { 6 Months Before Intervention } \\
\text { (Oct 2015-Mar 2016) } \\
\text { No. (\%) }\end{array}$ & $\begin{array}{c}\text { First 6 Months of Intervention } \\
\text { (Apr 2016-Sep 2016) } \\
\text { No. (\%) }\end{array}$ & $\begin{array}{c}\text { Second 6 Months of Intervention } \\
\text { (Oct 2016-Mar 2017) } \\
\text { No. (\%) }\end{array}$ & $\begin{array}{r}\text { Total } \\
\text { No. }\end{array}$ \\
\hline Pills & $2303(10.8)$ & $3378(8.4)$ & $3216(7.6)$ & 8897 \\
\hline DMPA-IM & $4292(20.0)$ & $9115(22.7)$ & $11,933(28.3)$ & 25,340 \\
\hline DMPA-SC & - & $6470(16.1)$ & $7803(18.5)$ & 14,273 \\
\hline Implants & $1926(9.0)$ & $2140(5.3)$ & $2262(5.4)$ & 6328 \\
\hline IUD & $217(1.0)$ & $280(0.7)$ & $254(0.6)$ & 751 \\
\hline Permanent methods ${ }^{b}$ & $21(0.1)$ & $94(0.2)$ & $123(0.3)$ & 238 \\
\hline Condoms & $12,662(59.1)$ & $18,646(46.5)$ & $16,540(39.3)$ & 47,848 \\
\hline Total & $21,421(100.0)$ & $40,123(100.0)$ & $42,131(100.0)$ & 103,675 \\
\hline Total CYPs & $\mathbf{7 0 7 3}$ & 11,491 & 13,009 & 31,573 \\
\hline
\end{tabular}

Abbreviations: CYP, couple-years of protection; DMPA-IM, intramuscular depot medroxyprogesterone acetate; DMPA-SC, subcutaneous depot medroxyprogesterone acetate; IUD, intrauterine device.

a Includes combined oral contraceptives and progesterone-only pills.

${ }^{b}$ Includes tubal ligation and vasectomy.

${ }^{c}$ Includes both male and female condoms.

delivered during the 12 months of project implementation. This translates to a mean of 6,854 units $(2,042$ CYPs $)$ per month, up from a mean of 3,570 units (1,179 CYPs) per month during the 6 months prior to project implementation, representing a substantial growth in the volume of methods provided across all sites. There were also notable and significant increases in the volume of each individual method provided through the project, including condoms (male and female), oral contraceptives, contraceptive implants, intrauterine devices (IUDs), and permanent methods $(P<.001$ for all methods).

\section{Injectables' Share of the Family Planning Market}

The increase in the share of injectables (DMPA-IM and DMPA-SC) was far greater than for other methods. The volume of injectables provided increased from 4,292 units during the 6 months before the project began (DMPA-IM only), to 15,585 units during the first 6 months of the intervention, and further to 19,736 during the second 6 months of project implementation (DMPA-IM and DMPA-SC combined during project implementation). As a result, there were notable changes in the mix of family planning methods provided across project sites, with injectables growing to represent a significantly larger proportion of methods provided during the first and second 6 months of project implementation (43\%) than before implementation (20\%) (Table 4$)$.

\section{Methods Provided by Service Delivery Channel}

The vast majority of all short-acting family planning methods provided through the project were delivered at the community level, either by VHTs or through mobile outreach clinics (Figure 2). The majority of implants (86\%) and IUD insertions $(59 \%)$ were also accessed in the community, at mobile outreach sites. DMPA-SC services were overwhelmingly provided at the community level by VHTs $(70 \%)$ or through mobile outreach services $(26 \%)$.

\section{Age Profile of Clients by Family Planning Method}

Overall, $42 \%$ of family planning services provided through the project across all project sites were delivered to young people (aged below 25). However, there were significant variances between methods. Notably, a significantly higher proportion of DMPA-SC units (43\%) were administered to young people than units of DMPAIM $(37 \%)$, oral contraceptives $(38 \%)$, implants

\author{
There were \\ significant \\ increases in the \\ volume of all \\ family planning \\ methods provided \\ through the \\ project.
}


FIGURE 2. Percentage Distribution of Family Planning Methods by Service Delivery Channel, 4 Districts of Uganda, April 2016-March 2017

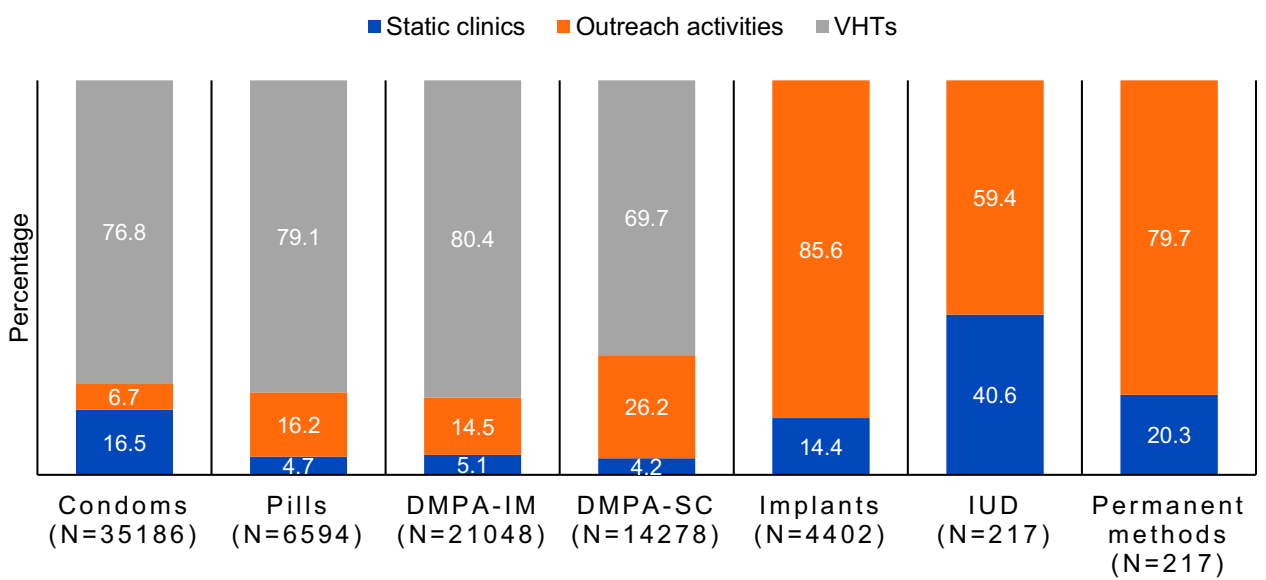

Abbreviations: DMPA-IM, intramuscular depot medroxyprogesterone acetate; DMPA-SC, subcutaneous depot medroxyprogesterone acetate; UUD, intrauterine device; VHT, village health team.

Note: Pills include combined oral contraceptives and progestin-only pills; condoms include male and female condoms; and permanent methods include tubal ligation and vasectomy.

$(22 \%)$, or IUDs (17\%) (Table 5$)$. Further analysis of DMPA-SC services by age and service delivery channel revealed that VHTs served a higher proportion $(45 \%)$ of young DMPA-SC clients than static clinics $(35 \%)$ or mobile outreach $(36 \%)$ (results not shown).

TABLE 5. Percentage Distribution of Family Planning Clients by Age and Method, 4 Districts of Uganda, April 2016-March 2017

\begin{tabular}{lccr}
\hline & \multicolumn{2}{c}{ Age Category } & \\
\cline { 2 - 3 } Method & $<25$ Years (\%) & $\geq 25$ Years (\%) & Total (N) \\
\hline Pills & 38.4 & 61.6 & 6594 \\
\hline DMPA-IM & 36.8 & 63.2 & 21,048 \\
\hline DMPA-SC & 42.6 & 57.4 & 14,273 \\
\hline Implants & 21.6 & 78.4 & 4402 \\
\hline IUD & 16.9 & 83.1 & 534 \\
\hline Permanent methods & 2.3 & 97.7 & 217 \\
\hline Condoms & 48.1 & 51.9 & 35,186 \\
\hline All methods & $\mathbf{4 2 . 1}$ & $\mathbf{5 7 . 9}$ & $\mathbf{8 2 , 2 5 4}$
\end{tabular}

Abbreviations: DMPA-IM, intramuscular depot medroxyprogesterone acetate; DMPA-SC, subcutaneous depot medroxyprogesterone acetate; IUD, intrauterine device.

Note: Pills include combined oral contraceptives and progestin-only pills; condoms include male and female condoms; and permanent methods include tubal ligation and vasectomy.

\section{Enabling Factors for the Provision of DMPA-SC at the Community Level}

From qualitative interviews, we identified several factors that enabled introduction of DMPA-SC.

\section{Training and Supportive Supervision}

Facility- and community-based providers recalled receiving comprehensive training on DMPA-SC and also responded positively to training on counseling skills for other methods as part of promoting voluntary family planning services.

We were taught comprehensive family planning methods including Sayana Press. About Sayana Press, we were taught about the size of injection, its strength, its user-friendliness compared to other injectables, storage, side effects, how it works. ... I think we covered a comprehensive package of Sayana Press. (Male facility-based provider, 10 years' experience)

However, some providers felt that refresher training on DMPA-SC would add value and enable them to solidify their learning.

The training was adequate; however, they should have organized another training so that they can refresh us properly. As a people, we may be forgetful or there may be something that we have not done the right way. So, if they come and organize a refresher meeting then you 
can correct your mistakes. (Female, VHT, 17 years' experience)

Most VHTs considered supervision important for strengthening their skills, improving quality of services, and building confidence among community members.

Yes, the in-charge of [facilities] is supporting us so much. When he comes to the ground [with other staff] for outreaches, people get to know that I am not doing it alone as an individual. So, we are supported. When we are trained in class, we assume we understand everything, but he comes and reminds you of how to prepare the drugs for administration. (Female, VHT, 10 years' experience)

\section{Reliable Commodity Supplies and Linkages}

A reliable supply of family planning commodities was considered essential for providing DMPA-SC and other family planning services. Most VHTs indicated that there were no challenges with DMPA-SC stock-outs and other materials or supplies necessary for its provision during project implementation.

From the time [DMPA-SC] was introduced, it has never been out of stock. I usually come here [RHU clinic] to request for it and it is provided, so there has not been any problem. (Female, VHT, 22 years' experience)

The strong relation between VHTs and facilities was considered important for enabling commodity resupply and referral of clients for long-acting methods.

First of all, it's a teamwork; I always work well with [health care providers] at the health center. We understand each other and also I see there is a lot of cooperation because they always call me and give me assignments and I am always willing to help. (Male, VHT, 7 years' experience)

\section{Community Acceptance}

Early engagement with, and sensitization of, community stakeholders was identified as beneficial to the smooth introduction of DMPA-SC.

I know about Sayana Press and we attended the district entry meeting where SP [Sayana Press] was introduced to the district. Because this is a new method, we needed to be aware. The orientation meeting gave us much information and knowledge. (Key informant interviewee, District Health Officer)

\section{Providers' View on Workload}

Many providers felt that DMPA-SC expanded the range of available family planning methods without significantly affecting their workload. DMPA-SC is similar to DMPA-IM, which is already being provided by active VHTs in their communities. Some facility-based providers reported that because DMPA-SC is easier to administer than DMPA-IM and implants, its introduction had actually enabled them to serve more clients in less time.

Family planning has long been there, and we have been providing family planning services to people, so Sayana Press is not any different. It is not complicated to administer. It is normal with us and we give it to people who want it easily. It is not any different from any other family planning method. (Female VHT, 10 years' experience)

It has reduced the workload because it is very easy to give.... It is very easy to give compared to Depo Provera and these other methods like Implanon. It has reduced our workload. (Female facility-based provider, 4 years' experience)

\section{Barriers to the Introduction of DMPA-SC}

Interviews with the key informants also identified a range of inhibiting factors.

\section{Inadequate Number of Trained Service Providers} Some key informants indicated that the number of community-based health workers trained to provide injectable contraceptives was still inadequate to meet the rising demand.

Only a few of us were trained. Some VHTs in some subcounties were not trained in family planning services, so we cover bigger areas and sometimes we are not able to reach some areas. Hence, people in those areas miss out on those services. It is important to increase the number of VHTs to publicize family planning services. (Female, VHT, 5 years' experience)

\section{Lack of Transportation}

High demand, large catchment areas, and poor transport connections left VHTs feeling stretched.

I am skilled and comfortable providing it [DMPA-SC] to people who need it. I also want to provide it to other people in far places only if I get [transport] facilitation. This acts as a barrier to me. . . lack of transport facilitation to reach women in the far areas. (Female, VHT, 10 years' experience)

\section{Community health workers were positive about the addition of DMPA-SC service delivery to their responsibilities.}


$96 \%$ of DMPA-SC units provided through the project were delivered at the community level.

\section{The share of injectables in the method mix grew from $20 \%$ at baseline to $43 \%$ at the end of the project.}

\section{Our pilot results reinforce that DMPA-SC is attractive to young people.}

\section{DISCUSSION}

This study documents the experience of an NGO in introducing DMPA-SC at the facility and community levels in 4 districts of Uganda. A number of themes emerge from the quantitative and qualitative data collected through the project.

\section{The Viability of Community-Based Distribution of DMPA-SC}

More than half of all methods, and $96 \%$ of DMPA-SC units, provided through the project were delivered at the community level outside of static clinics-either by VHTs or through mobile outreach teams. On average, each VHT provided 21 units of DMPA-SC per month, equating to an estimated 62 CYPs and 22 unintended pregnancies averted per VHT, per year. In the absence of service statistics from public health facilities, we do not have a complete picture of where clients accessed family planning services across all project districts. However, RHU's experience demonstrates that strengthening VHTs' capacity through training and ensuring continuous supply of contraceptive commodities can result in the provision of a high volume of family planning services at the community level.

\section{Potential for DMPA-SC Introduction to Increase the Share of Injectables in the Ugandan Method Mix}

Project data showed that there was a shift in the mix of family planning services provided during the project period, with injectables growing to represent $43 \%$ of all methods provided compared with just $20 \%$ prior to implementation. Project-level service data from a small number of service outlets (4 RHU static clinics, 40 VHTs, and 26 outreach sites) cannot be interpreted in the same way as population-based sample data such as from the Demographic and Health Surveys. However, the observed shift in the comparative balance of methods provided at the service level does provide insight into how the introduction of DMPA-SC could potentially further increase the share of injectables within the method mix in Uganda once it is rolled out nationally. Injectable contraceptives have become the most commonly used modern methods in a number of sub-Saharan African countries. ${ }^{18}$ The use of injectables has risen to about $15 \%$ to $20 \%$ of married women, equaling about $40 \%$ of all contraceptive use, with this percentage even higher in some countries. ${ }^{19-21}$

Importantly, while the introduction of DMPASC has the potential to impact the relative share of injectables within the method mix, this would not necessarily equate to a decline in the uptake of other methods in absolute numbers. Within the RHU project, for example, there was a significant increase in the volume of all contraceptive methods provided at project sites including long-acting methods. Furthermore, there is evidence to suggest that DMPA-SC has the potential to reach new acceptors of family planning. ${ }^{8}$ However, more rigorous research is needed on the possible impact of DMPA-SC introduction on the uptake of other methods.

It is important that, as with any new method, programmers use the introduction of DMPA-SC as an opportunity to reinforce access to a full range of methods. For example, programmers may consider giving community- and facility-based health workers refresher training on all methods when they are introducing DMPA-SC; strengthening links between service delivery points to enable referral for long-acting methods; and ensuring continuous availability of all contraceptive commodities across the family planning delivery system. These approaches, adopted by RHU in this project, were widely welcomed and identified through stakeholder interviews as enabling factors to the introduction of DMPA-SC.

\section{The Apparent Popularity of DMPA-SC Among Young People}

Project data on the proportion of family planning services provided by client age group reinforces existing evidence that DMPA-SC is attractive to young people. ${ }^{8,22}$ Nearly half (43\%) of all DMPASC units administered were provided to clients below 25 years of age-a significantly higher proportion than for all methods, except condoms. Other studies have found that DMPA-SC is popular among young people because of its convenience, the potential for discreet use without partner/parental detection, and the lower reported side effects than with some other methods. ${ }^{13,23,24}$ Service data show that a greater proportion of VHT clients were young (47\%) than static clinic clients $(35 \%)$ or mobile outreach clients $(36 \%)$. This could suggest that it is easier or more comfortable for young people to access contraceptives via VHTs, away from formal health settings.

\section{Both Supply- and Demand-Side Factors Facilitated Provision of DMPA-SC Services}

From qualitative interviews, we identified several factors that enabled introduction of DMPA-SC at 
the community level that may be of note for programmers and policy makers. VHTs and facilitybased providers valued the comprehensive family planning training; consistent availability of contraceptive commodities; and strong referral links (between public and NGO providers, and from VHTs to static facilities). Key informant interviews also found that engagement of community leaders before service delivery began was an important enabling factor.

However, a number of barriers and challenges remain. VHTs reported that the transport allowances they received through this project were insufficient to cover the cost of traveling to visit clients and to restock commodities at static clinics. There is need to review VHT support packages to better enable them to effectively do their work. In addition, the project trained only a limited number of active VHTs (10 in each district). Inadequate number of trained VHTs limited provision of DMPA-SC in the community. A 2015 study estimated that there were 179,175 VHTs in Uganda-30\% of whom did not have basic training at that time. ${ }^{25}$ As national rollout plans for DMPA-SC progress, training VHTs, and training them at volume, will likely become a major priority and challenge for government and partners alike.

\section{Study Limitations}

The project provided significant support in the form of training to the public sector to enable comprehensive service delivery in static facilities. However, due to the absence of data from publicsector facilities, the data presented do not offer a full picture of the intervention. Analysis is therefore limited to the volume of methods provided at RHU clinics, through mobile outreach, and by VHTs.

The absence of unique client identifiers across all service delivery points also limits analysis in several ways. First, it was not possible to identify how many individual clients were served by the project, and we should expect that a proportion of clients were provided with a method on multiple occasions during the course of the project, particularly users of short-acting methods including DMPA-SC. The absence of unique client identifiers across some service delivery platforms also means that it was not possible to track switching between methods.

Interviewees were purposively identified based on their role in the intervention and could have been tempted to offer positive views of the program. Given that some participants reported challenges, however, the selection process did not appear to bias the qualitative data collection to only those with positive views.

\section{CONCLUSIONS}

As questions about safety, efficacy, and acceptability of DMPA-SC are satisfactorily answered through rigorous research, ${ }^{26-28}$ programmers and policy makers turn their attention to operational questions about how DMPA-SC can be rolled out effectively to increase access to and reach those most in need. RHU's experience gives insight into one NGO's experience in introducing DMPA-SC at the community level in non-trial settings. The project focused heavily on community distribution through VHTs, which appears to have been an effective strategy for increasing service delivery and reaching young people. The views of project stakeholders in Uganda offer insight into how program teams, nationally and internationally, can roll out DMPA-SC to effectively reach those in most need of voluntary family planning.

Funding: The project, also known as the Sayana Press Learning Project (SPLP), was funded by the United States Agency for International Development (USAID) through the Sustainable Networks Project (SIFPO2) and implemented by Reproductive Health Uganda (RHU) in collaboration with the Ugandan Ministry of Health $(\mathrm{MOH})$ from April 2016 to March 2017.

Disclaimer: The opinions expressed in the paper are solely those of the authors and do not necessarily reflect the views of the funding agency.

Competing Interests: None declared.

\section{REFERENCES}

1. Family planning/contraception. World Health Organization website. http://www.who.int/news-room/fact-sheets/detail/ family-planning-contraception. Published February 8, 2018. Accessed August 2, 2018.

2. Sedgh G, Ashoford LS, Hussain R. Unmet Need for Contraception in Developing Countries: Examining Women's Reasons for Not Using a Method. New York: Guttmacher Institute; 2016. https://www. guttmacher.org/report/unmet-need-for-contraception-indeveloping-countries. Accessed October 3, 2018.

3. Spieler J. Sayana® Press: can it be a "game changer" for reducing unmet need for family planning? Contraception. 2014;89(5): 335-338. CrossRef. Medline

4. Kaunitz AM, Darney PD, Ross D, Wolter KD, Speroff L. Subcutaneous DMPA vs. intramuscular DMPA: a 2-year randomized study of contraceptive efficacy and bone mineral density. Contraception. 2009;80(1):7-17. CrossRef. Medline

5. Khan ME, Bhatnagar I. Challenges in introducing new contraceptive methods: a case study of India. Int Q Community Health Educ. 2015;35(4):387-401. CrossRef. Medline

6. Prettyman J. Subcutaneous or intramuscular? Confronting a parenteral administration dilemma. Medsurg Nurs. 2005;14(2):93-98; quiz 99. Medline 
7. World Health Organization Department of Reproductive Health and Research (WHO/RHR); Johns Hopkins Bloomberg School of Public Health/Center for Communication Programs (CCP), Knowledge for Health Project. Family Planning: A Global Handbook for Providers (2018 update). Baltimore and Geneva: CCP and WHO; 2018. http://www.fphandbook.org/. Accessed October 3, 2018.

8. Stout A, Wood S, Barigye G, Kaboré A, Siddo D, Ndione I. Expanding access to injectable contraception: results from pilot introduction of subcutaneous depot medroxyprogesterone acetate (DMPA-SC) in 4 African countries. Glob Health Sci Pract. 2018; 6(1):55-72. CrossRef. Medline

9. Uganda Bureau of Statistcs (UBOS); ICF. Uganda Demographic and Health Survey 2016. Kampala, Uganda and Rockville, MD: UBOS and ICF; 2018. https://www.dhsprogram.com/publications/ publication-fr333-dhs-final-reports.cfm. Accessed October 1, 2018

10. Uganda: commitment maker since 2012. Family Planning 2020 (FP2020) website. http://www.familyplanning2020.org/uganda. Accessed October 3, 2018.

11. Krueger K, Akol A, Wamala P, Brunie A. Scaling up community provision of injectables through the public sector in Uganda. Stud Fam Plann. 2011;42(2):117-124. CrossRef. Medline

12. Government of Uganda, Ministry of Health (MOH). Health Sector Strategic Plan III 2010/11-2014/15. Kampala, Uganda: $\mathrm{MOH}$; 2010. http://www.health.go.ug/docs/HSSP_II_2010.pdf. Accessed October 3, 2018.

13. Stanback J, Mbonye AK, Bekiita M. Contraceptive injections by community health workers in Uganda: a nonrandomized community trial. Bull World Health Organ. 2007;85(10):768-773. CrossRef. Medline

14. Government of Uganda, Ministry of Health (MOH). The National Policy Guidelines and Service Standards for Sexual and Reproductive Health and Rights. Kampala, Uganda: $\mathrm{MOH} ; 2012$.

15. Turinawe EB, Rwemisisi JT, Musinguzi LK, et al. Selection and performance of village health teams (VHTs) in Uganda: lessons from the natural helper model of health promotion. Hum Resour Health. 2015;13(1):73. CrossRef. Medline

16. Impact 2: an innovative tool for measuring the impact of reproductive health programmes. Marie Stopes International website. https:// www.mariestopes.org/what-we-do/our-approach/our-technicalexpertise/impact-2/. Accessed October 3, 2018.

17. Hoke T, Brunie A, Krueger K, et al. Community-based distribution of injectable contraceptives: introduction strategies in four sub-Saharan African countries. Int Perspect Sex Reprod Health. 2012;38(4): 214-219. CrossRef. Medline
18. United Nations, Department of Economic and Social Affairs, Population Division. Trends in Contraceptive Use Worldwide 2015. New York: United Nations; 2015. http://www.un.org/en/ development/desa/population/publications/pdf/family/ trendsContraceptiveUse2015Report.pdf. Accessed October 3, 2018.

19. Family Planning 2020 (FP2020). FP2020: The Way Ahead: 2016-2017. Washington, DC: FP2020; 2017. http://progress. familyplanning2020.org/en. Accessed October 3, 2018.

20. Ross JA, Agwanda AT. Increased use of injectable contraception in sub-Saharan Africa. Afr J Reprod Health. 2012;16(4):68-80. Medline

21. Seiber EE, Bertrand JT, Sullivan TM. Changes in contraceptive method mix in developing countries. Int Fam Plan Perspect. 2007; 33(3): 117-123. Medline

22. Cover J, Lim J, Namagembe A, Tumusiime J, Drake JK, Cox CM. Acceptability of contraceptive self-injection with DMPA-SC among adolescents in Gulu District, Uganda. Int Perspect Sex Reprod Health. 2017;43(4):153-162. CrossRef. Medline

23. Morris JL, Rushwan $\mathrm{H}$. Adolescent sexual and reproductive health: the global challenges. Int J Gynaecol Obstet. 2015;131(suppl 1): S40-S42. CrossRef. Medline

24. Laryea DO, Ankobeah F, Morhe ESK, Amoako YA, Spangenberg K. Characteristics and contributory factors for injectable contraceptive usage among women in Kumasi, Ghana. Contracept Reprod Med. 2016;1(1):8. CrossRef. Medline

25. Pathfinder International; Ideal Development Consults Limited. National Village Health Teams (VHT) Assessment in Uganda. Kampala, Uganda: Ministry of Health [Uganda]; 2015. http:// library.health.go.ug/publications/service-delivery-public-health/ health-education/national-village-health-teams. Accessed on July 20, 2018.

26. Prabhakaran S, Sweet A. Self-administration of subcutaneous depot medroxyprogesterone acetate for contraception: feasibility and acceptability. Contraception. 2012;85(5):453-457. CrossRef. Medline

27. Cameron ST, Glasier A, Johnstone A. Pilot study of home selfadministration of subcutaneous depo-medroxyprogesterone acetate for contraception. Contraception. 2012;85(5):458-464. CrossRef. Medline

28. Beasley A, White KOC, Cremers S, WesthoffC. Randomized clinical trial of self versus clinical administration of subcutaneous depot medroxyprogesterone acetate. Contraception. 2014;89(5):352-356. CrossRef. Medline

Peer Reviewed

Received: March 23, 2018; Accepted: September 17, 2018; First Published Online: November 14, 2018

Cite this article as: Odwe G, Gray K, Kyarimpa A, Obare F, Nagendi G. Introduction of subcutaneous depot medroxyprogesterone acetate (DMPA-SC) injectable contraception at facility and community levels: pilot results from 4 districts of Uganda. Glob Health Sci Pract. 2018;6(4):71 1-722. https:// doi.org/10.9745/GHSP-D-18-00117

(c) Odwe et al. This is an open-access article distributed under the terms of the Creative Commons Attribution 4.0 International License (CC BY 4.0) which permits unrestricted use, distribution, and reproduction in any medium, provided the original author and source are properly cited. To view a copy of the license, visit http:// creativecommons.org/licenses/by/4.0/. When linking to this article, please use the following permanent link: https:// doi.org/10.9745/GHSP-D-18-00117 